\title{
Pelatihan Teamwork Pada Anggota Pengelola RPTRA Malaka Sari, Jakarta Timur
}

\author{
Erik Saut H Hutahaean ${ }^{1}$, Yuarini Wahyu Pertiwi ${ }^{1}$, Hema Dayita Pohan ${ }^{1}$, Tiara Anggita \\ Perdini ${ }^{2,}$, Farida Novitasari ${ }^{1}$ \\ ${ }^{1}$ Fakultas Psikologi; Universitas Bhayangkara Jakarta Raya; Jl. Perjuangan 081, Marga Mulya, \\ Bekasi Utara; Telp. 02188955882/ +622188955871; e-mail: erik.saut@dsn.ubharajaya.ac.id, \\ yuarini.wp@dsn.ubharajaya.ac.id, hema.dayita@dsn.ubharajaya.ac.id, \\ farida.novitasari17@mhs.ubharajaya.ac.id \\ 2 Fakultas Psikologi; Universitas Persada Indonesia YAI; Jl. Pangeran Diponegoro No.74, \\ RT.2/RW.6, Kenari, Kec. Senen, Kota Jakarta Pusat; Telp. 0213926000; e-mail: \\ tiaraanggitaperdini@gmail.com \\ *Korespondensi: e-mail: tiaraanggitaperdini@gmail.com
}

\begin{abstract}
Child Friendly Integrated Public Space (RPTRA) is one of the communities established by the DKI Jakarta government in order to build a communication platform. RPTRA is managed by a group of individuals who have good intentions in managing it. Not only that, managers are sometimes faced with other tasks, which also require the role of all management members. As in other groups, group dynamics occur within them. For example, in the form of things throwing work responsibilities, reporting to each other, resulting in the process of working together being hampered and making the work process not smooth. The implementation of the webinar activity is carried out with the asynchronous method, in the sense that the participants and the team do not conduct the seminar on a live broadcast. But by communicating in WhatsApp groups, questions and evaluations using the g-form, delivering material through YouTube media. Through outreach activities which lasted for approximately five hours and carried out asynchronously, the counseling provided benefits for the participants.
\end{abstract}

Keywords: Malaka Sari Village, RPTRA manager, Team Work

\begin{abstract}
Abstrak
Ruang Publik Terpadu Ramah Anak (RPTRA) merupakan salah satu komunitas yang didirikan pemerintah DKI Jakarta guna untuk membangun wadah berkomunikasi. RPTRA dikelola oleh sekelompok individu yang berniat baik dalam melakukan pengelolaannya. Tidak hanya itu, pengelola terkadang dihadapkan dengan tugas-tugas lainnya, yang juga membutuhkan peran dari seluruh anggota pengelola. Seperti pada kelompok lainnya, dinamika kelompok terjadi didalamnya. Misalnya yaitu berupa hal-hal melempar tanggung jawab kerja, saling melapor satu dengan lainnya, sehingga mengakibatkan proses kerja bersama menjadi terhambat dan membuat proses kerja menjadi tidak lancar. Pelaksanaan kegiatan webinar dilakukan dengan metode asinkroni, dalam artian bahwa peserta dan tim tidak melakukan seminar secara siaran live. Melainkan dengan berkomunikasi di dalam WhatsApp group, pertanyaan dan evaluasi menggunakan g-form, penyampaian materi melalui media youtube. Melalui kegiatan penyuluhan yang berlangsung kurang lebih selama lima jam dan dilakukan secara asinkroni penyuluhan memberikan manfaat bagi peserta.
\end{abstract}

Kata kunci: Kelurahan Malaka Sari, Pengelola RPTRA, Kerjasama 
Erik Saut H Hutahaean, Yuarini Wahyu Pertiwi, Hema Dayita Pohan, Tiara Anggita Perdini, Farida Novitasari

\section{Pendahuluan}

Kerjasama merupakan sesuatu yang sangat berharga di dalam proses kerja di dalam kelompok, khususnya dalam hal menangani tugas-tugas yang tidak bisa dijalankan secara individual (Schmutz, Meier, \& Manser, 2019). Salah satu indikator lancarnya kegiatan suatu organisasi atau komunitas terlihat pada kinerja yang dihasilkan, terutama terkait dengan Sumber Daya Manusia (SDM) (Wartini, 2016). Sumber Daya Manusia (SDM) dapat dipengaruhi oleh banyak faktor internal seperti pengetahuan, semangat, kepuasan, komitmen, kedisiplinan, dan masih banyak lagi (Dunggio, 2013). Faktor-faktor tersebut dapat mempengaruhi kerja sama tim yang pada akhirnya dapat memberikan dampak kepada organisasi itu sendiri (Masyithah, Adam, \& Tabran, 2018). Dalam menjalankan proses kerjasama diperlukan ada proses kebersamaan, sikap saling berperan aktif terhadap tugas yang seharusnya diselesaikan, dan pada akhirnya akan mencerminkan suatu keberhasilan kelompok (Satria, Nurmalina, \& Kusuma, 2021). Ukuran keberhasilannya adalah pencapaian-pencapaian penyelesaian kegiatan yang menjadi bagian dari program kerja (Lestari, Nulhaqim, \& Irfan, 2015).

Setiap kelompok kerja memiliki rencana giat yang harus dilaksanakan dan diselesaikan pada kurun waktu tertentu. Bahkan juga termasuk giat yang bersifat mendadak, karena sangat mungkin suatu kelompok dibutuhkan peran dan bantuannya dari kelompok lainnya (Cahyo, Djuwita, \& Wasidi, 2019). Seperti halnya dengan kelompok kerja pengelola Ruang Publik Terpadu Ramah Anak yang terdapat di Kelurahan Malaka Sari Jakarta Timur. Bekerja tidak hanya untuk menjalankan programnya sendiri, tetapi juga harus terintegrasi dengan program giat yang diberikan oleh Pemerintah Daerah DKI Jakarta. Harapannya, RPTRA bisa ikut membantu kota DKI Jakarta agar dapat mencapai suatu raihan status kota layak anak serta menyediakan ruang terbuka hijau bagi publik. RPTRA sendiri bertujuan menyediakan ruang terbuka untuk memenuhi hak anak agar anak dapat hidup, tumbuh, berkembang dan berpartisipasi secara optimal sesuai dengan harkat dan martabat kemanusiaan ("Ruang Publik Terpadu Ramah Anak (RPTRA)," 2020).

Berdasarkan gambaran awal yang diperoleh dari pengelola RPTRA antara satu dengan yang lainnya yang memiliki karakteristik berbeda-beda, cenderung saling melempar kesalahan, bahkan melempar tanggung jawabnya karena mengganggap ada orang lain yang bisa diandalkan. Keadaan ini membuat terjadinya beberapa hambatan di dalam menjalankan giatnya, seperti misalnya berupa tanggung jawab yang melemah dan terganggunya proses melakukan kegiatan yang membutuhkan energi cukup besar (Tse, Fung, Nakamura, \& Csikszentmihalyi, 2018). Belum lagi terjadi adanya pandemic covid-19 yang menjangkiti para pengelola ataupun anggota keluarganya, cenderung semakin melemahkan proses kerja bersama diantar para pengola RPTRA Kelurahan Malaka Sari (Vanni et al., 2020). Pengelola juga menyadari bahwa diperlukan adanya kesadaran mengenai cara menjalankan team work di dalam kelompok kerjanya, yang dilakukan dengan membuka pola berfikir mengenai proses kerja bersama dalam perspektif yang lebih terbuka. Karenanya pengelola membutuhkan ada 
masukan tambahan dari pihak eksternal yang dapat membantu para pengelola untuk mengatasi kendala-kendala yang terjadi di dalam menjalankan program kerjanya.

\section{Metode Pelaksanaan}

Kegiatan ini dilaksanakan pada hari Sabtu, 24 Juli 2021 dengan melibatkan 32 peserta yaitu para pengelola RPTRA. Kegiatan dimulai pukul 10.00 hingga 15.00. Kegiatan pengabdian masyarakat ini dilakukan secara asynkroni dengan menggunakan beberapa aplikasi. Adapun aplikasi-aplikasi yang digunakan yaitu whatsapp, youtube, dan google form. Sebelum kegiatan dimulai, tim membagikan link pretest terlebih dahulu untuk kemudian diisi oleh peserta. Hal ini bertujuan untuk mengetahui gambaran awal pemahaman para peserta tarkait teamwork. Tim dan para pengelola RPTRA berkomunikasi melalui aplikasi whatsapp group, yang dimana sebelumnya telah dibagikan materi mengenai teamwork pada aplikasi youtube.

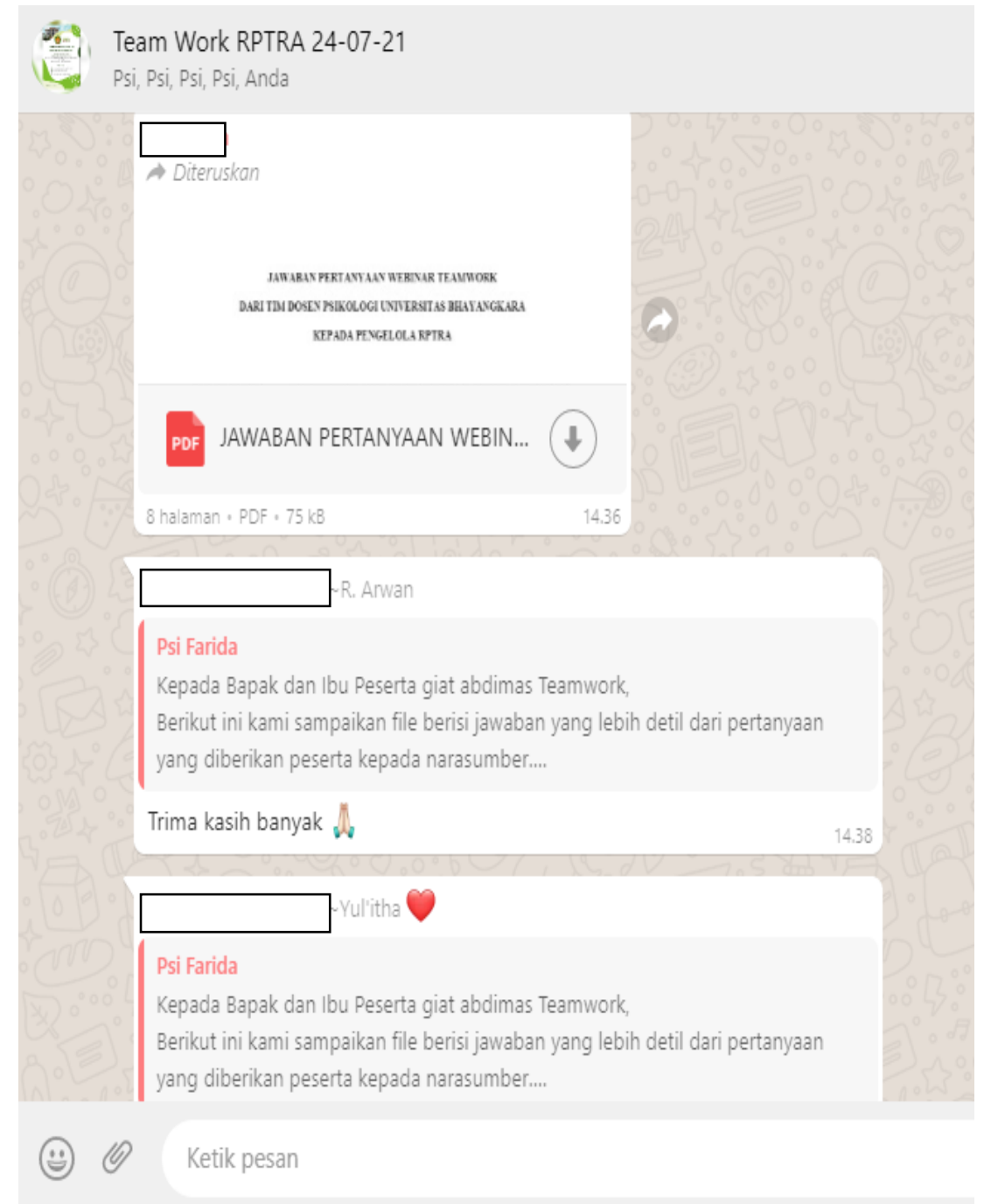

Sumber: Hasil Pelaksanaan (2021)

Gambar 1. Gambaran Whatsapp group kegiatan 
Erik Saut H Hutahaean, Yuarini Wahyu Pertiwi, Hema Dayita Pohan, Tiara Anggita Perdini, Farida Novitasari

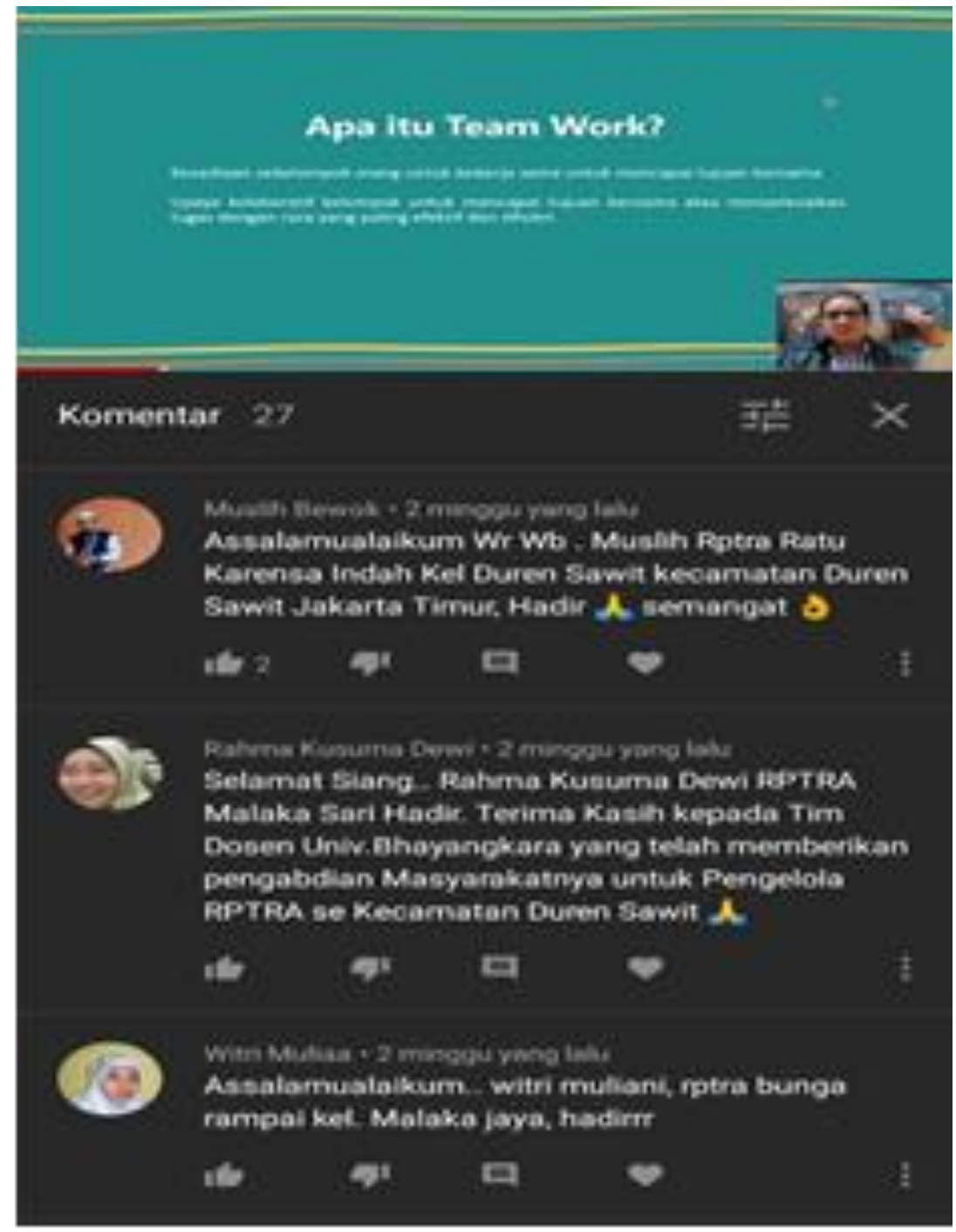

Sumber: Hasil Pelaksanaan (2021)

Gambar 2. Gambaran pemberian materi melalui youtube

Materi yang dijelaskan adalah mengenai pemahaman seputar apa itu teamwork? bagaimana konsep teamwork dapat berjalan? dan bagaimana membangun teamwork yang baik? Selain pemaparan materi, ada juga kegiatan diskusi dan Tanya jawab. Dalam kegiatan tersebut, tim mengumpulkan pertanyaan peserta melalui google form dan menjawabnya melalui whatsapp group dengan cara mengirimkan file dalam bentuk format pdf. Dalam file tersebut sudah ada pertanyaan serta jawabanya yang telah diisi oleh para narasumber. Setelah sesi diskusi, tim memberikan link post-test untuk diisi kembali oleh para peserta, hal ini bertujuan untuk melihat gambaran pemahaman peserta mengenai teamwork setelah pemaparan materi. Jika dirincikan maka urutan sesi kegiatan adalah sebagai berikut: a) pemberian link pretest, b) pemberian materi melalui youtube yang disampaikan oleh bapa Erik Saut H Hutahaean, S.Psi., M.Si, c) diskusi dan Tanya jawab melalui whatsapp group yang didampingi oleh ibu Yuarini Wahyu Pertiwi S.Psi., S.H., M.Psi, Psikolog dan ibu Hema Dayita Pohan M.Psi., Psikolog, d) pemberian link posttest, e) penutup. 


\section{Hasil dan Pembahasan}

\subsection{Persiapan Kegiatan}

Persiapan dilakukan untuk menyusun langkah-langkah dan mengetahui hal-hal yang dibutuhkan untuk melaksanakan keguatan sosialisasi terhadap pengurus RPTRA Malaka Sari. Sebelum kegiatan pengabdian masyarakat dilaksanakan, tim pelaksana melakukan wawancara kepada beberapa peserta guna untuk melihat gambaran permasalahan yang ada dalam RPTRA. Dari giat tersebut, tim pelaksana memutuskan untuk menjadikan 'teamwork' sebagai tema kegiatan. Pengangkatan tema ini didasari dari hasil wawancara singkat antara tim pelaksana dengan beberapa peserta pengelola RPTRA. Hasil wawancara menunjukan bahwa banyak peserta yang mengeluhkan kerjasama tim RPTRA. Beberapa diantaranya mengeluhkan keterlibatan anggota yang kurang, saling mengandalkan antar anggota, dan beberapa anggota yang selalu fokus terhadap kesalahan anggota lain. Oleh karena itu pengelola RPTRA dirasa membutuhkan pemahaman dan pengetahuan yang lebih dalam lagi mengenai kerjasama tim, sehingga kedepannya bisa membangun tim RPTRA menjadi lebih sehat dan kompak.

\subsection{Deskripsi Peserta}

Secara umum audiens pada kegiatan ini adalah pihak-pihak yang tertarik untuk mengenal proses team work dalam mengelola suatu organisasi, khususnya dalam mengelola tim pada pengurus RPTRA Malaka Sari. Berlangsungnya kegiatan dilaksanakan oleh beberapa orang tim pelaksana. dihadiri oleh para tamu undangan, dan para peserta yang dalam hal ini adalah seluruhnya adalah pengelola RPTRA. Dalam kegiatan ini, tim mencoba mendapatkan data deskriptif berdasarkan tiga kategorial: kategori jenis kelamin, kategori pendidikan akhir, dan kategori posisi sebagai pengelola RPTRA. Adapun gambaran dan data lengkap mengenai para peserta yang hadir berdasarkan Jenis Kelamin, Pendidikan Akhir Serta Posisi adalah sebagai berikut.

Tabel 1. Deskripsi Peserta

\begin{tabular}{|c|c|c|c|}
\hline & & Jumlah & Total \\
\hline \multirow{2}{*}{$\begin{array}{c}\text { Jenis } \\
\text { Kelamin }\end{array}$} & Laki-Laki & 13 & \multirow{10}{*}{32} \\
\hline & Perempuan & 19 & \\
\hline \multirow{3}{*}{$\begin{array}{c}\text { Pendidikan } \\
\text { Akhir }\end{array}$} & SMA/SMK & 16 & \\
\hline & D3 & 5 & \\
\hline & S1 & 11 & \\
\hline \multirow{5}{*}{$\begin{array}{c}\text { Posisi } \\
\text { Pengelola } \\
\text { RPTRA }\end{array}$} & Sekretaris & 8 & \\
\hline & Bendahara & 3 & \\
\hline & Pokja & 14 & \\
\hline & $\begin{array}{l}\text { Sarana } \\
\text { Prasarana }\end{array}$ & 4 & \\
\hline & Koordinator & 3 & \\
\hline
\end{tabular}

Sumber: Hasil Pelaksanaan (2021)

Pada tabel 1 dijelaskan gambaran subjek berdasarkan jenis kelamin, pendidikan akhir yang ditempuh dan juga posisi atau bagian dalam pengelola RPTRA. Hasilnya dapat dilihat bahwa peserta dengan jenis kelamin laki-laki berjumlah 13 orang dan perempuan berjumlah 19 orang. Peserta yang menempuh pendidikan sampai SMA/SMK berjumlah 16 orang, pendidikan D3 5 orang, dan lulusan S1 sebanyak 11 orang. Kegiatan ini juga mendapatkan peserta yang 
Erik Saut H Hutahaean, Yuarini Wahyu Pertiwi, Hema Dayita Pohan, Tiara Anggita Perdini, Farida Novitasari

terdiri dari beberapa posisi, yaitu peserta dengan posisi sekretaris berjumlah 8 orang, bendahara 3 orang, pokja 14 orang, posisi sarana dan prasarana berjumlah 4 orang, dan peserta dengan posisi coordinator berjumlah 3 orang. Kelanjutannya berdasarkan lamanya tergabung dalam pengelola RPTRA dapat dilihat pada tabel 2

Tabel 2. Deskripsi Peserta

\begin{tabular}{ccccc}
\hline \multicolumn{5}{c}{ Usia menjadi pengelola RPTRA } \\
\hline 1 tahun & 2 tahun & 3 tahun & 4 tahun & 5 tahun \\
\hline 2 anggota & 9 anggota & 8 anggota & 9 anggota & 4 anggota \\
\hline & Total $=32$ \\
\hline
\end{tabular}

Sumber: Hasil Pelaksanaan (2021)

Tim juga memperoleh data tentang masa keterlibatan peserta dalam kepengurusan pengelolaan RPTRA, rincian masa keterlibatan adalah ada peserta yang bergabung selama 1 tahun, 2 tahun, 3 tahun, 4 tahun, hingga masa keterlibatan yang paling lama adalah 5 tahun. Pada tabel 2. Dapat dilihat sebaran peserta kegiatan berdasarkan berapa lama mereka tergabung sebagai pengelola RPTRA. Hasilnya yaitu 2 anggota telah bergabung selama 1 tahun, 9 anggota bergabung selama 2 tahun, 8 anggota terhitung bergabung selama 3 tahun, 9 anggota 4 tahun, dan 4 anggota telah bertahan sebagai pengelola RPTRA selama 5 tahun. Total peserta pada kegiatan ini yaitu 32 orang.

\subsection{Pelaksanaan Kegiatan}

Kegiatan ini dilaksanakan dimulai dengan memberikan pertanyaan seputar team work, hal ini dilakukan sebagai upaya tim untuk mendapatkan informasi mengenai wawasan dari audiens tentang makna kerjasama dalam suatu struktur kepengurusan. Sebelum pemaparan materi dilakukan, para peserta terlebih dulu diberikan link form pretest. Form tersebut terdiri empat pertanyaan terkait teamwork. Empat pertanyaan tersebut yaitu:

Tabel 3. Form Pertanyaan

\begin{tabular}{cc}
\hline No & Pertanyaan \\
\hline 1 & Apa yang anda ketahui mengenai teamwork? \\
\hline 2 & Apa yang dimaksud dengan team? \\
\hline 3 & Bagaimana cara membangun teamwork? \\
\hline 4 & Bagaimana cara mendorong team untuk bekerja?
\end{tabular}

Sumber: Hasil Pelaksanaan (2021)

Pada pertanyaan pertama dan kedua yaitu menanyakan pemahaman peserta akan definisi teamwork, pertanyaan ketiga yaitu solusi yang dipakai peserta dalam membangun teamwork yang baik, dan pertanyaan keempat mengenai bagaimana membuat tim bekerja secara bersama-sama. Kemudian setelah form pretest dibagikan, selanjutnya adalah pemaparan materi yang dijelaskan oleh pemateri bapa Erik Saut H Hutahaean S.Psi., M.Si. Dalam kegiatannya, dijelaskan pengertian teamwork, konsep tim, langkah-langkah membangun teamwork yang baik dan juga bagaimana membuat tim bekerja bersama. Kemudian setelah kegiatan pemberian materi telah selesai, selanjutnya akan diberikan link posttest dengan pertanyaan sama persis seperti link pretest. 
Tabel 4. Jawaban Peserta

\begin{tabular}{|c|c|c|}
\hline & Pretest & Posttest \\
\hline $\begin{array}{l}\text { Apa yang anda ketahui } \\
\text { mengenai Teamwork? }\end{array}$ & $\begin{array}{c}\text { Sekelompok orang yang } \\
\text { menyelesaikan tugas } \\
\text { bersama, saling bekerja sama } \\
\text { untuk mencapai tujuan yang } \\
\text { sama, sebuah keterampilan, } \\
\text { kerjasama dalam tim, } \\
\text { kemampuan berkomunikasi } \\
\text { antar teman, belajar bersama }\end{array}$ & $\begin{array}{c}\text { Sekelompok orang yang } \\
\text { bekerja sama untuk } \\
\text { mencapai suatu tujuan, } \\
\text { bekerja bersama dengan } \\
\text { kesediaan, kesediaan } \\
\text { sekelompok orang untuk } \\
\text { bekerjasama dan berjuang } \\
\text { bersama dalam mencapai } \\
\text { tujuan }\end{array}$ \\
\hline $\begin{array}{l}\text { Apa yang dimaksud } \\
\text { dengan Team? }\end{array}$ & $\begin{array}{l}\text { Kelompok, suatu kumpulan, } \\
\text { sekelompok orang yang } \\
\text { bekerja bersama, sekumpulan } \\
\text { individu dalam satu kelompok, } \\
\text { salah satu keterampilan, terdiri } \\
\text { dari dua orang atau lebih }\end{array}$ & $\begin{array}{c}\text { Together everyone achieves } \\
\text { more, bekerja bersama } \\
\text { mengambil peran dan } \\
\text { bertanggung jawab memiliki } \\
\text { tolak ukur dan mencapai } \\
\text { keberhasilan, regu atau } \\
\text { kelompok }\end{array}$ \\
\hline $\begin{array}{l}\text { Bagaimana cara } \\
\text { membangun } \\
\text { Teamwork? }\end{array}$ & $\begin{array}{c}\text { Tujuan yang dama dan } \\
\text { komunikasi yang baik, } \\
\text { mengenal karakter dan } \\
\text { peranan masing masing } \\
\text { kelompok, memiliki visi misi } \\
\text { sama, saling percaya dan } \\
\text { menghargai, lingkungan kerja } \\
\text { yang kondusif, menyamakan } \\
\text { persepsi }\end{array}$ & $\begin{array}{l}\text { Kenali kondisi awal dan } \\
\text { pahami aturan kerjasama } \\
\text { konflik, memiliki ikatan } \\
\text { emosi beradaptasi dan } \\
\text { berintegritas, berkomunikasi } \\
\text { dengan baik dan benar }\end{array}$ \\
\hline $\begin{array}{c}\text { Bagaimana cara } \\
\text { mendorong team untuk } \\
\text { bekerja? }\end{array}$ & $\begin{array}{l}\text { Dukungan dan komunikasi } \\
\text { yang baik, memberikan } \\
\text { semangat satu sama lain, visi } \\
\text { misi yang sama, memotivasi } \\
\text { dan melakukan pekerjaan } \\
\text { bersama, memberikan } \\
\text { kepercayaan terhadap tugas, } \\
\text { saling mengingat dan } \\
\text { membantu }\end{array}$ & $\begin{array}{c}\text { Menciptakan rasa } \\
\text { kepercayaan dan } \\
\text { membangun hubungan } \\
\text { interpersonal yang kuat, } \\
\text { perjelas fungsi dan peran } \\
\text { dalam kelompok, seluruh tim } \\
\text { fokus terhadap target, } \\
\text { memberi dukungan dan } \\
\text { semangat }\end{array}$ \\
\hline
\end{tabular}

Sumber: Hasil Pelaksanaan (2021) membantu

Dilihat dari tabel diatas (tabel 4), jawaban para peserta telah mengalami perubahan dari pretest ke posttest. Pada pretest ditemukan banyak varian jawaban peserta namun pada posttest, varian jawaban menjadi lebih sedikit dan rata-rata peserta menjawab sama.

\subsection{Manfaat Untuk Para Peserta}

Upaya tim melaksanakan kegiatan abdimas ini memang belum diarahkan kepada sesuatu yang tarafnya tinggi, karena jangkauan kebermanfaatan yang dirancang dalam kegiatan ini adalah untuk memberikan wawasan pengetahuan. Tetapi, meskipun kebermanfaatan ini berada dalam ruang lingkup pada wilayah pengetahuan audiensi atau peserta. Secara general kegiatan ini memberikan input tambahan bagi tim pengelola RPTRA Kelurahan Malaka Sari Jakarta Timur terkait dengan menambah pemahaman dan peningkatan kesadaran mengenai pentingnya proses kerja secara bersama-sama, dan bagaimana membangun kerjasama yang baik serta sehat. Input ini kemudian dijadikan sebagai modal mendasar untuk lebih memotivasi peserta agar mengambil bagian ataupun berpartisipasi di dalam kegiatan-kegiatan internal lainnya, maupun kegiatan dadakan yang datangnya dari pihak luar atau pihak eksternal.

Efek dari munculnya kesadaran tentang cara mengaplikasikan proses team work nantinya akan memunculkan rencana-rencana jangka pendek, mengingat dari saat kegiatan abdimas ini dilaksanakan, pengelola RPTRA akan disibukan dengan kegiatan-kegiatan 
Erik Saut H Hutahaean, Yuarini Wahyu Pertiwi, Hema Dayita Pohan, Tiara Anggita Perdini, Farida Novitasari

mendukung pemerintah terkait dengan vaksinasi di lingkungan sekitara wilayah RPTRA Malaka Sari. Secara tidak langsung ternyata kegiatan ini juga dimanfaatkan oleh pengurus pengelola RPTRA Malaka Sari untuk dijadikan wadah berkumpul secara daring, ditengah-tengah situasi pandemic yang sangat kecil memberikan peluang untuk dapat berkumpul secara tatap muka langsung.

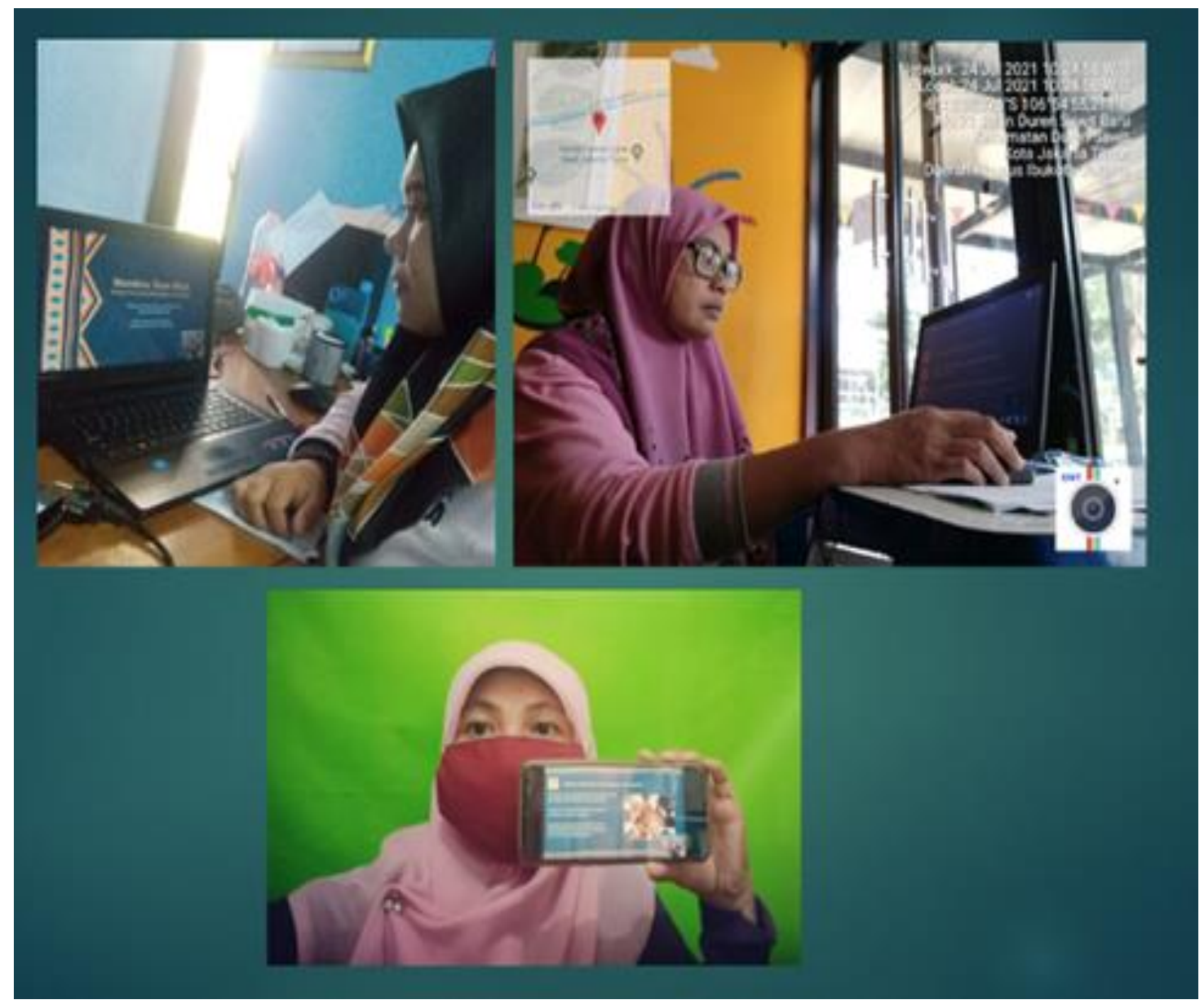

Sumber: Hasil Pelaksanaan (2021)

Gambar 3. Peserta Kegiatan Pengabdian Masyarakat Teamwork

\section{Kesimpulan}

Kegiatan memberikan manfaat bagi para peserta khususnya dalam hal meningkatkan pemahaman tentang makna team work, dan memunculkan kesadaran tentang penitngnya team work di dalam melakukan pengelolaan seluruh kegiatan RPTRA Malaka Sari. Melalui kegiatan penyuluhan ini para pengelola RPTRA Kelurahan Malaka Sari Jakarta Timur mendapatkan pengetahuan, wawasan dan pemahaman yang baru dari hal yang pernah dipahami sebelumnya mengenai kerjasama tim. Melalui kegiatan ini juga para pengelola dapat melakukan evaluasi baik evaluasi diri maupun evaluasi kelompok, mengenasi peranannya di dalam kelompok tersebut yang kemudian untuk menilai apakah proses kerja yang dijalankannya sudah diarahkan untuk tujuan yang sama, dan diselesaikan secara bersama-sama juga. Hal ini 
penting, mengingat kelompok merupakan satu dan RPTRA merupakan komunitas besar. Pemahaman yang diterima peserta melalui kegiatan ini dapat dimanfaatkan untuk mengenali langkah-langkah memperbaiki diri sehingga dapat berperan aktif di dalam kelompok.

\section{Daftar Pustaka}

Cahyo, F. T., Djuwita, P., \& Wasidi. (2019). Studi Deskriptif bentuk Permainan Kegiatan Kepramukaan dalam Mengembangkan Sikap Tanggung Jawab Kerjasama dan Tolong Menolong pada Interaksi Sosial Siswa SD Negeri 68 Kota Bengkulu. Jurnal Pembelajaran Dan Pengajaran Pendidikan Dasar, 2(1), 60-70.

Dunggio, M. (2013). Semangat Dan Disiplin Kerja Terhadap Produktivitas Kerja Karyawan Pada Pt. Jasa Raharja (Persero) Cabang Sulawesi Utara. Jurnal Riset Ekonomi, Manajemen, Bisnis Dan Akuntansi, 1(4), 523-533.

Lestari, R. B., Nulhaqim, S. A., \& Irfan, M. (2015). Teamwork Pengembangan Kemitraan (Studi Kasus Kelompok Kerja Pengembangan Kemitraan dalam Penangulangan Kemiskinan di Kota Bogor). EMPATI: Jurnal IImu Kesejahteraan Sosial, 4(1), 1-21. https://doi.org/10.15408/empati.v4i1.9763

Masyithah, S. M., Adam, M., \& Tabran, M. (2018). Analisis Pengaruh Kompensasi, Kerjasama Tim dan Budaya Organisasi terhadap Kepuasan Kerja serta Dampaknya pada Kinerja Karyawan PT. Bank Muamalat Cabang Banda Aceh. Simen, 9(1), 50-59.

Pratiwi, E. S., \& Herlawati, H. (2019). Sistem Informasi Penjualan Katering Berbasis Web Pada CV. Saung Alit Telaga Murni Cikarang Barat Eka. INFORMATION SYSTEM FOR EDUCATORS AND PROFESSIONALS, 3(2), 177-188.

Ruang Publik Terpadu Ramah Anak (RPTRA). (2020, November 30). Jakarta.go.id. Retrieved from https://jakarta.go.id/artikel/konten/7159/ruang-publik-terpadu-ramah-anak-rptra

Satria, H., Nurmalina, \& Kusuma, Y. Y. (2021). Penerapan Model Treasure Hunt Untuk Meningkatkan Keterampilan Kerjasama Siswa Sekolah Dasar Kelas IV SDM 002 Penyasawan Kecamatan Kampar. Indonesian Research Journal on Education, 1(1), 1124.

Schmutz, J. B., Meier, L. L., \& Manser, T. (2019). How effective is teamwork really? The relationship between teamwork and performance in healthcare teams: A systematic review and meta-analysis. BMJ Open, 9(9), 1-16. https://doi.org/10.1136/bmjopen-2018-028280

Tse, D. C. K., Fung, H. H., Nakamura, J., \& Csikszentmihalyi, M. (2018). Teamwork and flow proneness mitigate the negative effect of excess challenge on flow state. Journal of Positive Psychology, 13(3), 284-289. https://doi.org/10.1080/17439760.2016.1257059

Vanni, G., Materazzo, M., Santori, F., Pellicciaro, M., Costesta, M., Orsaria, P., ... Buonomo, O. C. (2020). The Effect of coronavirus (COVID-19) on breast cancer teamwork: A multicentric survey. In Vivo, 34, 1685-1694. https://doi.org/10.21873/invivo.11962 
Erik Saut H Hutahaean, Yuarini Wahyu Pertiwi, Hema Dayita Pohan, Tiara Anggita Perdini, Farida Novitasari

Wartini, S. (2016). Strategi Manajemen Konflik Sebagai Upaya Meningkatkan Kinerja Teamwork Tenaga Kependidikan. Jurnal Manajemen Dan Organisasi, 6(1), 64. https://doi.org/10.29244/jmo.6.1.64-73 